\title{
APUNTES PARA UN MAPA INTELECTUAL DE CHILE DURANTE EL CENTENARIO: 1900-1925
}

\author{
F. JAVIER PINEDO \\ Universidad de Talca, Chile \\ jpinedo@utalca.cl
}

\section{RESUMEN}

Se intenta mostrar los principales conceptos utilizados por un grupo de pensadores chilenos que escribieron en los primeros 25 años del siglo XX y cuya fecha central es el primer Centenario de la Independencia, celebrado en 1910. Un periodo histórico que se inicia con el siglo y se cierra con la promulgación de una nueva Constitución política en 1925, la cual marcó una diferencia respecto a la época anterior en cuestiones sociales (el progresivo reemplazo de la antigua oligarquía por sectores de clase media), políticas (la aceptación de un sistema presidencialista y de leyes que incorporan a los nuevos sujetos sociales) y las expresiones culturales y literarias.

Palabras claves: Pensamiento chileno, Centenario, identidad nacional, modernidad.

\section{ABSTRACT}

The main concepts used by a group of Chilean thinkers who wrote in the first 25 years of the 20th century, and whose central date is the first Centenary of independence celebrated in 1910 , are shown in this article. A historical period started with the new century, and ended with a new Constitution in 1925, which marked a difference from the previous era, on social issues (the progressive replacement of the old oligarchy by middle-class sectors), political issues (the acceptance of a presidential system, and laws which were incorporated into the new social subjects), and cultural and literary expressions.

Keywords: Chilean thought Centennial, National identity, Modernity.

\section{Qué es un mapa intelectual}

Por un mapa intelectual entendemos un gráfico que nos muestre las rutas circuladas por un grupo de pensadores en relación con sus diagnósticos de la realidad, sus proyectos políticos y sus puntos de contacto en sus visiones de país y en las soluciones que propusieron, aglutinadas en matrices de ideas. Un mapa intelectual puede organizarse destacando diferentes criterios, tales como resaltar el lugar y vida de los autores, ya su

\section{F. Javier Pinedo}

Doctor en Literatura por la Universidad de Lovaina (Bélgica). Director, docente e investigador del Instituto de Estudios Humanísticos de la Universidad de Talca (Chile). Director de la Revista Universum. Autor de artículos y libros sobre Literatura e Historia de las Ideas en América Latina. Entre sus libros destacan Chile 1968-1988 (1988) con José Luis Gómez-Martínez; El pensamiento chileno en el siglo XX (1999) con Eduardo Devés y Rafael Sagrado y La Patria Interrumpida. Latinoamericanos en el exilio. Siglos XVIII-XX (2010) con Carlos Sanhueza.

Este trabajo forma parte del proyecto de investigación: «Entre Nuestra inferioridad económica' (1912) de Fco. Antonio Encina, y 'En vez de la miseria' (1958), de Jorge Ahumada. Intelectuales, ensayistas y creadores literarios chilenos entre 1900 y 1960»; financiado por Fondecyt - Chile, con el número 1110251.
Apuntes para un mapa intelectual de Chile durante el Centenario: 1900-1925

E. JAVIER PINEDO origen social, o bien lo más importante: los conceptos con que marcaron su pensamiento y su época.

Entre los más relevantes se encuentran Agustín Ross Edwards (1844-1926), Enrique Mac-Iver (1845-1922), Nicolás Palacios (1854-1911), Alejandro Venegas (1870-1922), Enrique Molina Garmendia (1871-1964), Guillermo Subercaseaux (1872-1959), Juan Enrique Concha (1873-1931), Francisco Antonio Encina (1874-1965), Alberto Edwards (1874-1932), Tancredo Pinochet Le-Brun, 


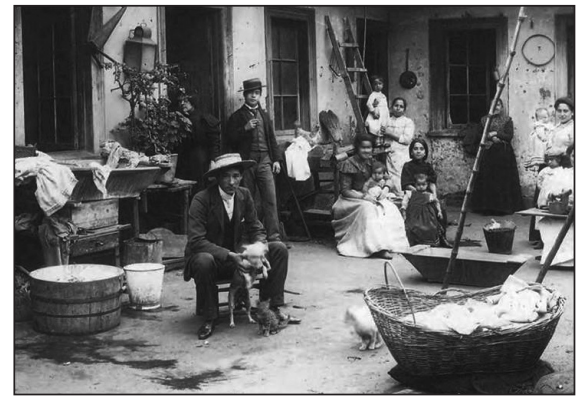

1879-1957, Luis Emilio Recabarren (1876-1924), y algunos más².

Se trata de un conjunto de abogados, banqueros, filósofos, profesores de liceo, líderes populares, autodidactas, políticos, quienes reflexionaron críticamente en torno a ciertos aspectos de Chile, reflexiones establecidas en matrices eidéticas que continuarían debatiéndose a lo largo del siglo XX.

2

Cada uno de estos autores ha sido estudiado en detalle. Por ejemplo, Miguel da Costa (1999). Recabarren es probablemente quien mayor atención ha recibido. Para Venegas es conocido el análisis de Martín Pino y los de Cristián Gazmuri para el conjunto. Sobre la época recomiendo a Sergio Grez, Gabriel Salazar, Sofía Correa y Gonzalo Vial, desde un punto de vista histórico; y a Bernardo Subercaseaux, desde el cultural.

3

El mayor es Mac Iver, que en 1910 tiene 65 años. Palacios, 56; Molina, Venegas, Encina y Recabarren, entre 35 y 40 , y el más joven es Tancredo Pinochet, con 30 años. Desde este punto de vista, es problemático hablar de generación. Sus ideas tampoco son homogéneas, pero tienen en común la denuncia social y el escribir en torno a 1910.

4

Para Cecilia Sánchez (1999), el intento por transformar los problemas del país en enfermedades sociales, los llevó a actuar como médicos. De hecho, Alejandro Venegas usó el seudónimo Doctor Julio Valdés Cange y el título de doctor no es casual.

5

El pensar sólo para ellos mismos, se observa palmariamente en el subtítulo del libro de Nicolás Palacios (1904), Raza Chilena. Libro escrito por un chileno y para los chilenos.

6

Son testimonios de Armando Donoso, Domingo Melfi, y Jerónimo Lagos Lisboa. Ver Andy Daitsman (1999).

Apuntes para un mapa intelectual de Chile durante el Centenario: 1900-1925

F. JAVIER PINEDO

Si bien de diferentes edades, a los miembros de este grupo, que, en medio de las celebraciones realizó un balance negativo del país, se le conoce como «Generación del Centenario» ${ }^{3}$.

\section{Rol del intelectual en el Chile del Cente- nario}

Se trata de un pensador que se ve a sí mismo como la conciencia lúcida de la sociedad, pues cree saber lo que sucede en ella y poseer la solución para los problemas que denuncia ${ }^{4}$; un pensador que opina desde sí mismo y para un país que es el suyo. Un pensador insular para un país insular ${ }^{5}$. Excepto Recabarren, Encina y Subercaseaux (que fueron diputados), los intelectuales de la «Generación del Centenario» no estuvieron ligados al poder político, aunque la política constituye un tema central para todos ellos. Son pensadores que en sus obras intentan representar (criticar) al país completo: la clase alta, la media y la popular. Con la interrupción temprana de Luis E. Recabarren, que incorpora al mundo obrero y su necesaria organización, se desarrolla el sujeto social popular que es el más avanzado de una época en la que todavía no aparecen indígenas o mujeres como productores de opinión social.

Sus lecturas más inspiradoras fueron la generación española del 98, Marx y Lenin y más tarde Spengler (traducido al español en 1923). Pero, además, han dejado constancia de conocer a Tolstoi, Turgenef, Dostoievski, Balzac, Zola, Dickens, Kropotkin, Darwin, Spencer, Engels, Reclus, Renán, George ${ }^{6}$ y

\section{7}

Uso indistintamente los conceptos de «pensadores» $\mathrm{e}$ 《intelectuales» aunque no todos coinciden con la figura del intelectual profesional moderno. Son más bien iniciadores de esa actividad que la ejercen de forma espontánea presionados por las propias circunstancias.

8

José Enrique Rodó y el poeta Juan Zorrilla de San Martín representaron a Uruguay en

algunos otros hoy prácticamente desconocidos: Novicow, Carnegie, Onofre Avendaño, Lapouge, Uriel Hancock.

Es, en definitiva, un conjunto de pensadores entre los cuales encontramos a representantes de la oligarquía tradicional (Agustín Ross Edwards, Guillermo Subercaseaux, Juan Enrique Concha), las capas medias de provincia (Nicolás Palacios, Enrique Molina, Alejandro Venegas), a representantes de la inmigración europea (Enrique Mac- Iver, Tancredo Pinochet Le-Brun), y a Luis E. Recabarren, proveniente del mundo popular.

Para Hernán Godoy (1999, p. 254), los pensadores de comienzos de siglo XX se refieren a temas concretos de la sociedad, mientras que en los del siglo XIX (Lastarria, Bilbao) predominó «la exposición doctrinaria de ideas políticas y filosóficas con escasa referencia a la realidad inmediata». Es decir, Godoy considera a los primeros más prácticos y menos «ideológicos»: «Ambos grupos muestran una clara preocupación política, pero mientras los del siglo pasado cifraban sus esperanzas en nuevas Constituciones y en vagas reformas de la sociedad y del hombre, los autores de comienzos del siglo XX apuntan a cambios políticos, económicos y culturales específicos, en consonancia con los diagnósticos concretos y particulares que formulan en sus obras». Y muchos de ellos, como Tancredo Pinochet Le-Brun, Francisco A. Encina o Alejandro Venegas, plantearon propuestas políticas y educacionales concretas. En este sentido, son más pensadores que intelectuales académicos ${ }^{7}$.

En relación a la caracterización que se ha hecho del intelectual latinoamericano, a saber, un «arielista» mayoritariamente continuador de Rodó, de pensamiento idealista y conservador, señorial, de espaldas al mundo real y contrario al progreso técnico (F. Marsal, 1970), pensamos que es errónea y pese a que el Ariel (1900) fue leído, su lectura no influyó en la conciencia de los pensadores de la época y por tanto no hay, o muy poca «Torre de marfil», y aunque algunos son «aristócratas», no son aristocratizantes ${ }^{8}$. En cambio sí

el Centenario de la Independencia de Chile, y Rodó leyó en el Parlamento el discurso «El Centenario de Chile», donde aportó su posición americanista. (José Enrique Rodó, 1975). Sin embargo, el arielismo afectó al sector más «literario», como en los poetas chilenos Pedro Prado y Ernesto A. Guzmán (René de Costa, 2011), y el ensayista Armando Donoso quien escribe un artículo en 1917 lamentando la muerte de Rodó. 
encontramos denuncia y compromiso social, acción a favor del mundo popular y críticas al statu quo.

En mi opinión, domina una actitud marcada por un análisis económico y sociológico provocado por el impacto de la pobreza, la injusticia y la necesidad de desarrollo. Ni siquiera entre humanistas como Enrique Molina, se observa tan presente el espíritu de Rodó, pues también este sector buscó soluciones educacionales prácticas.

\section{Un Centenario. Dos países}

El siglo XIX chileno, sin desconocer los conflictos internos (revoluciones de 1851, 1859 y 1891) y externos (guerras contra Perú y Bolivia en 1836 y 1879), fue una época en que el país creció económicamente y se estabilizó políticamente, lo que se manifiesta en un aumento de la producción cultural (libros y periódicos), la fundación de la Universidad de Chile (1843) y la llegada de una pléyade de intelectuales extranjeros, como Andrés Bello, Juan B. Alberdi, Domingo F. Sarmiento, Ignacio Domeyko y Claudio Gay, quienes contribuyeron a desarrollar las ciencias y las humanidades. Pero, también se caracteriza por el surgimiento de enormes fortunas económicas producidas por la actividad minera, que consolidaría a la llamada «aristocracia chilena» 9 .

Desde finales del siglo XIX, en cambio, surge una serie de pensadores que mostraban un conjunto de problemas sociales, económicos y políticos, percibidos como una muy profunda «crisis» social. Esos pensadores, denominados «aguafiestas» ${ }^{10}$, han pasado a la historia por sus denuncias de las divisiones sociales, de un sistema parlamentario ineficaz, de los graves problemas en materia de educación y sobre todo, de la presencia de una pobreza que no se condescendía con los afanes de modernización, a los que aspiraba un país con enormes fortunas individuales.

Así, una parte de Chile celebraba con optimismo las fiestas del Centenario debido a los logros de los primeros cien años de vida independiente: un consagrado orden institucional ${ }^{11}$, un importante quehacer cultural, o cuestiones puntuales como la inauguración del ferrocarril Los Andes a Mendoza -un antiguo sueño de integración con Argentina, y cuya locomotora llevaba el nombre de Eugenio María de Hostos, intelectual puertorriqueño que había enseñado en Chile los años finales del siglo XIX- y la inauguración de importantes edificios emblemáticos, como el Museo de Bellas Artes, la Biblioteca Nacional, la estación de trenes Mapocho, y el embellecimiento y extensión de la ciudad de Santiago ${ }^{12}$. Todo parecía funcionar bien.

Mientras esto sucedía, los «aguafiestas» ponían en evidencia las contradicciones y limitaciones de la sociedad chilena desde una mirada múltiple: nacionalista, antiliberal, socialista, anticlerical y antioligárquica, exigiendo una mayor participación del Estado en el desarrollo económico.

Junto a lo anterior, una serie de huelgas y muertes de obreros marcaban la fragilidad del modelo político y la intransigencia de la élite gobernante ${ }^{13}$. En este sentido, la sociedad chilena de 1910 está determinada por una serie de debates que reflejan la crisis: la situación obrera y el socialismo, el inicio de la clase media y el decaimiento de la oligarquía, las discusiones entre parlamentarismo y presidencialismo, y el tema educacional.

Estas iniciativas para superar la crisis, que no siempre tuvieron éxito, afirmaron a nuevos protagonistas sociales y contribuyeron a la redacción de la Constitución de 1925, como

flexión», en Instituto de Historia de la Universidad Católica de Chile, http://www.hist. puc.cl/cinfo/Articulos/gazmuri25.html

11

Como lo muestra, por ejemplo, el sucesivo reemplazo de autoridades a la muerte del presidente Pedro Montt (16 de agosto de 1910), que es sucedido, cumpliendo la ley, por el vicepresidente, Elías Fernández Albano, quien a su vez, por una cruel casualidad, también fallece al poco tiempo (e 6 de septiembre), exactamente a doce días de la celebración del Centenario, el 18 de septiembre de 1910, asumiendo finalmente la presidencia Emiliano Figueroa Larraín. Esta situación, a juicio de muchos testigos nacionales $y$ extranjeros, probaba la solidez de la democracia chilena.

12

Debemos mencionar la inauguración en Santiago, el 2 de septiembre de 1900, de un sistema de tranvías eléctricos administrado por empresas norteamericanas, inglesas y alemanas (de Ramón, 1985).

13

Huelgas en Valparaíso, en 1903; Santiago, 1905; Antofagasta, en 1906; Magallanes, 1919 y 1920, donde las reivindicaciones sociales se mezclaron con la intransigencia de los poderosos. La culminación más trágica fue la matanza obrera de 1907 acaecida en la Escuela Santa María de lquique, realizada por un general de apellido Silva Renard, con un número de muertos entre 500 y 1.500 mineros con sus mujeres e hijos.

Apuntes para un mapa intelectual de Chile durante el Centenario: 1900-1925

F. JAVIER PINEDO 


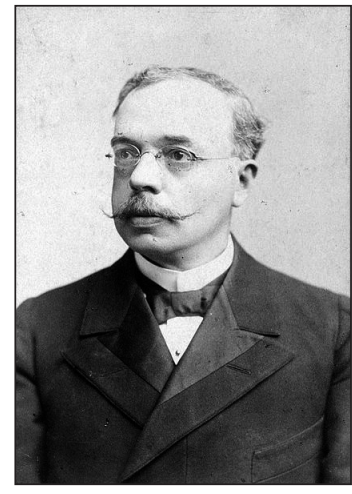

Enrique Mac-Iver.

14

El tema de la crisis continuará en las décadas siguientes en textos como Balance patriótico, de Vicente Huidobro (1925); La eterna crisis chilena (1931); Cómo salir de la crisis, (1931) de Carlos Keller; Aún es tiempo (1942), Crisis sin fronteras (1974), de Eduardo Frei Montalva; Chile, un caso de desarrollo frustrado (1959), de Aníbal Pinto; En vez de la miseria (1958), La crisis integral de Chile (1966), de Jorge Ahumada, entre muchos otros.

15

Otro grupo que compartió la opinión crítica al estado de cosas para el Chile del Centenario lo constituyeron los artistas anarquistas. Bernardo Subercaseaux (2004) califica a esta corriente como un grupo heterogéneo que buscaba "una modernidad distinta a la del liberalismo oligárquico, una modernidad que, alimentada por la ilustración de pueblo, terminaría por demoler la 'falsedad de la democracia burguesa', construyendo un nuevo edificio social basado en la libertad y la naturaleza». Como integrantes de este grupo de artistas identifica a Fernando Santiván, Augusto D'Halmar, José Santos González Vera, José Domingo Gómez Rojas, Manue Rojas, Antonio Acevedo Hernández, Roberto Meza Fuentes, Pedro Luna, Camilo Mori, Vicente Huidobro y Julio Ortiz de Zárate; el grupo de «Los Diez» y todavía Pedro Prado, Acario Cotapos, Alberto Ried, Armando Donoso y Julio Bertrand, así como a los participantes de La «Colonia Tolstoyana», que intentó llevar a la práctica el anarquismo con Fernando Santiván, Manue Magallanes Moure y Augusto D'Halmar a la cabeza.

\section{Apuntes para un mapa intelectual de Chile durante el Centenario:} 1900-1925

F. JAVIER PINEDO

expresión del poder de decisión política de estos nuevos protagonistas. Es decir, una sociedad cambiante, en la que, con la misma celeridad que se van rotando los apellidos en el poder, se modifican los discursos en las tribunas sociales y políticas y las expresiones artísticas y literarias. No obstante, la producción económica se mantendría estable: un país minero monoproductor.

El historiador Gonzalo Vial habla de un naufragio de proyecto nacional con posterioridad a la guerra civil de 1891, que se mantuvo presente a lo largo del siglo XX y que estallaría en el Golpe militar de 1973. Una historia que se inicia con un suicidio presidencial, José Manuel Balmaceda, en 1891, y que concluye con el de Salvador Allende en 1973. Entre ambos hechos, la historia de un país que ha intentado el desarrollo, la modernidad y la justicia social sin conseguirlo, o sólo a medias.

En torno a esta realidad, se agruparon conservadores y liberales, modernizadores y anti modernizadores, católicos y laicos, vanguardistas y criollistas, nacionalistas e internacionalistas. Estudiarlos nos permitirá comprender el funcionamiento intelectual del conjunto de autores analizados: sus fuentes de pensamiento, sus proyectos políticos y, especialmente, la manera en cómo intentaron la construcción del país a lo largo del siglo XX. Veremos algunos de ellos.

\section{La «cuestión social» como expresión de una sociedad en crisis}

La imagen de Chile como una sociedad en crisis es probablemente el tema más importante impuesto por los del Centenario: un país que no logra resolver sus problemas ${ }^{14}$. Parte de la explicación de vivir en una sociedad en crisis tiene su origen en la llamada «cuestión social» (Cruzat y Tironi, 1999), que denuncia la negativa situación de los trabajadores y que se expresó en ciertos programas socialistas y anarquistas, surgidos durante el periodo ${ }^{15}$.

El tema tiene su origen en el libro $\mathrm{La}$ Cuestión Social, que Augusto Orrego Luco publicó en Valparaíso en 1887, en el cual se

16

Entre los antecedentes menciona los textos de Malaquías Concha, líder del Partido Demócrata, Movimiento obrero en Chile, 1888; Arturo Alessandri, futuro presidente, que en 1893 publicó Habitaciones obreras; Valentín Letelier, Los pobres, 1896; Juan Enrique Concha Subercaseaux, Cuestiones obreras, memoria para titularse de abogado, 1899

describía la pobreza y la emigración de los campesinos a la ciudad, que constituían grupos de seres marginales que pululaban pos las calles sin medios de subsistencia. Estas ideas impactaron con rapidez la sensibilidad de la época en los grupos sociales y sus representantes en la prensa, el parlamento y la opinión pública (Grez Toso, 1995, p. 21) ${ }^{16}$.

Francisco Antonio Encina, por su lado, señala que entre 1895 y 1900 irrumpió en Chile una ola de pesimismo, que se explicitó en la conferencia de Enrique Mac Iver, La Crisis Moral en Chile; pero, además, menciona otros factores que coadyuvaron a producir este estado de ánimo negativo: «El origen inmediato y tangible del fenómeno fue el fracaso de las ilusiones cifradas en el triunfo de la revolución de 1891». [...] «La profunda y prolongada crisis económica de 1894 a 1900 agravó desde otro ángulo, el pesimismo». Luego destaca que "hacia 1895 empezaron a hacerse sentir las consecuencias de un fenómeno que, en estos momentos, abre una angustiosa interrogante sobre los destinos de los pueblos hispanoamericanos. El contacto con civilizaciones más avanzadas y la difusión de la enseñanza crean necesidades que desequilibran moralmente al individuo, si al mismo tiempo no se desarrollan en él las aptitudes económicas necesarias para subvenir en ellas». [...] «El último factor que contribuyó a la gestación de la racha de pesimismo de 1895-1900 fue la muerte espiritual del régimen portaliano» ${ }^{17}$ (Encina, 1999, p. 78).

Otro antecedente, todavía, lo constituye el folleto de Emilio Rodríguez Mendoza (1899), Ante la decadencia, en el que denuncia las enormes diferencias entre ricos y pobres y propone la educación como salida, pero con una orientación norteamericana: «Hay pues, desde luego, una marcada diversidad de ideales entre anglosajones y latinos. El primero, busca la educación práctica; el segundo, es más efecto al título, al relumbrón». Una posición contraria a la de Rodó, pues aquí se intenta imitar a los Estados Unidos (e Inglaterra) como norma económica social y cultural ${ }^{18}$

17

Con «régimen portaliano», Encina se refiere a Diego Portales, Ministro conservador de mediados del XIX, a quien Encina señalaba como el promotor del ordenamien- to jurídico y del progreso económico.

18

En todo caso el Ariel, de Rodó, se publicó justo un año más tarde, en 1900. 
El abogado y diputado radical, Enrique Mac-Iver (1900), en su texto Crisis moral de la República, fue uno de los que más intensamente insistió en que el país vivía sumergido en un estado de anomia e igual que el resto criticó a la educación como la causante de la degradación de un país que no lograba realizar lo que se esperaba de él.

¿De dónde procedía el malestar? ¿De dónde la percepción de que la realidad completa (educación, cultura, modo de ser, ideas o ausencia de ideas), es decir, el conjunto de nociones y valores en los que funciona esta sociedad, no eran útiles para enfrentar el presente? A veces las críticas nos parecen subjetivas, como si el malestar proviniera de una situación personal ${ }^{19}$.

Como sea, Enrique Mac Iver cuya percepción del malestar es una de las que más profundamente marcó la época: «Voy a hablaros sobre algunos aspectos de la crisis moral que atravesamos; pues yo creo que ella existe y en mayor grado y con caracteres más perniciosos para el progreso de Chile que la dura y prolongada crisis económica que todos palpan».

Y luego su famosa frase con la que dibujó para siempre la sociedad chilena: «Me parece que no somos felices; se nota en el malestar que no es de cierta clase de personas ni de ciertas regiones del país, sino de todo el país y de la generalidad de los que lo habitan. La holgura antigua se ha trocado en estrechez, la energía para la lucha de la vida en laxitud, la confianza en temor, las expectativas en decepciones. El presente no es satisfactorio y el porvenir aparece entre sombras que producen intranquilidad».

Más adelante insiste en la idea del malestar como una síntesis de cuestiones raciales y culturales, de funcionamiento del Estado, de prácticas sociales y políticas, con una admiración por los Estados Unidos similar a Rodríguez Mendoza y Francisco A. Encina: «Es esa moralidad, esa alta moralidad, hija de la educación intelectual y hermana del patriotismo, elemento primero del desarrollo social y del progreso de los pueblos; es ella la que formó los cimientos de la grandeza de Estados Unidos» (Mac Iver, 1900, p. 17).

En otros casos, la percepción de la crisis se asocia (aunque no de forma exclusiva) con una situación económica y social, pero descrita directamente desde el punto de vista de los pobres, como en Luis Emilio Recabarren, un obrero tipógrafo que se erige como una de las voces más críticas. Para él, la división es tan profunda que ni siquiera existe una identidad nacional común, sino sólo la de las respectivas clases sociales. "No es posible mirar a la nacionalidad chilena desde un solo punto de vista, porque toda observación resultaría incompleta. Es culpa común que existan dos clases sociales opuestas, y como si esto fuera poco, todavía tenemos una clase intermedia que complica más este mecanismo social de los pueblos» (Recabarren, 1910, p. 11).

A un siglo de la independencia, Recabarren expone las razones de la no existencia de una nación como un elemento común para el conjunto de habitantes. Su balance es el más negativo: «La verdad de que en cien años de vida republicana se constata en progreso paralelo de dos circunstancias: el progreso económico de los crímenes y de los vicios en toda la sociedad. La vida del conventillo y de los suburbios no es menos degradada que la vida del presidio».

De aquí surge la importancia de la organización popular: en ocasiones incluso, Recabarren habla como un apóstol que intenta redimir a los abandonados de este mundo: «Yo estimo que la patria es el hogar satisfecho y completo, y la libertad solo existe cuando existe este hogar. La enorme muchedumbre que puebla campos y ciudades, ¿tiene acaso hogar? ¡No tiene hogar...! ¡No tiene hogar...! $¡ Y$ el que no tiene hogar no tiene libertad! Todos los grandes creadores y fundadores de la economía política han afirmado este principio: ${ }_{i} \mathrm{El}$ que no tiene hogar no tiene libertad!»

Se trata de un pensador crítico y denunciador que habla desde lo que ve: la pobreza, por lo que no necesita citar a otros autores para demostrar que está diciendo la verdad. Y lo que ve es un proletariado bestializado, al que se le debe un hogar, dignidad, moralidad e igualdad social. Luis E. Recabarren llega a no sentirse incorporado al Estado que celebra el aniversario: «i (...) miro el pasado a través de mis 34 años y no encuentro en toda mi vida una circunstancia que me convenza que he tenido patria y que he tenido libertad...! (...) ¡Celebrar la emancipación política del pueblo! Yo considero un sarcasmo esta expresión. Es quizás una burla irónica».

Similar a la perspectiva de Recabarren, surgieron otras obras que todavía nos impactan por la fuerza de sus argumentos. Son considerados los clásicos del Centenario. Hay
19

Para Godoy (1999), la crisis fue real y entre otras razones aduce que «...la guerra civil de 1891 contribuyó a acentuar la declinación del papel predominante que Chile jugaba en América, quedando rezagado frente a Brasil y Argentina».

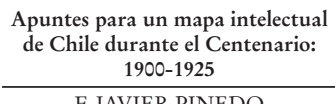

F. JAVIER PINEDO 


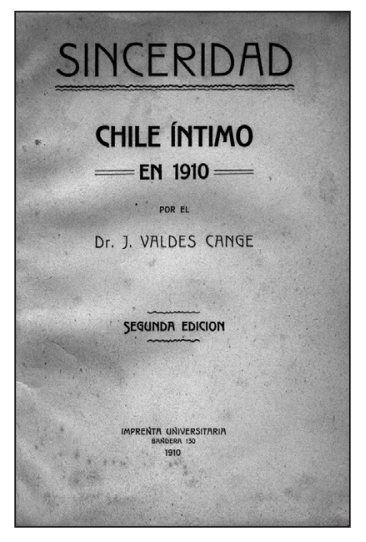

Cubierta de Sinceridad.

20

Una interesante relación entre Recabarren y Venegas se encuentra en Kaempfer (2011).

21

El historiador Ricardo Donoso (1963, p. 107) nos recuerda las imágenes del maestro que lo formó: «Don Alejandro Venegas nos impresionó desde la primera hora por su espíritu crítico, su coraje cívico y la profundidad de sus conocimientos. Cuando hablaba de los escritores de su predilección, a quienes profesaba una admiración sin límites, un Benito Jerónimo Feijóo, o un Manuel José Quintana, su palabra adquiría un tono profético, profundamente impresionante. Era inclinado a la crítica social...».

Apuntes para un mapa intelectual de Chile durante el Centenario: 1900-1925

F. JAVIER PINEDO consenso en que, entre estas obras, además de las mencionadas, se debe incluir la de Alejandro Venegas, firmada con el pseudónimo de Dr. Julio Valdés Cange. Se trata de una serie de cartas dirigidas al presidente, Ramón Barros Luco (1910-1915), sobre los problemas que aquejan a la sociedad chilena del Centenario, y en las que muestra la distancia que va del orgullo autoproclamado a la degradada realidad:

Acabamos de celebrar nuestro Centenario y hemos quedado satisfechos, complacidísimos de nosotros mismos. No hemos esperado que nuestros visitantes regresen a su patria y den su opinión, sino que nuestra prensa se ha calado la sotana y el roquete, ha empuñado el innecesario, y entre reverencia y reverencia, nos ha proclamado pueblo cultísimo y sobrio, ejemplo de civismo, de esfuerzo gigantesco, admirablemente preparado para la vida democrática, respetuoso de sus instituciones y de los sabios integérrimos políticos que lo dirigen, en una palabra, espejo milagroso de virtudes en que deben mirarse todos los pueblos que aspiren a ser grandes» (Valdés Cange, 1910, p. 8$)^{20}$.

Para explicar la crisis, Venegas pone énfasis en el cambio del patrón oro al papel moneda: «El régimen del curso forzoso de papel moneda, juntamente con aumentar la fortuna de los grandes agricultores a expensas del pueblo trabajador, ha dado a la vida de los chilenos una nueva orientación, fijándoles como Norte la acumulación de riquezas. (...) La impresión más viva que recibe el viajero observador al estudiar nuestra organización social, es la que le produce el contraste entre la gente adinerada y pobres, esto es explotadores y explotados; no existe la clase media...» (Valdés Cange, 1910, p. 204).

En efecto, basta contemplar las fotografías de la vida cotidiana del Centenario para observar personajes populares descalzos, cubiertos de ropas rotas, y con rostros sufrientes. Junto a ellos, en otras imágenes, la élite asistiendo al Sporting Club de Viña del Mar, con elegantes trajes traídos de París o de Madrid, porque aquí no hay industrias que puedan hacer vestidos, sombreros o zapatos de esa calidad.

Venegas utiliza palabras como «órgano gangrenado", "pecho carcomido por el cáncer», «charca cenagosa», «acequias pestilentes», para caracterizar una pobreza que no era nueva sino una prolongación del Chile popu- lar del siglo anterior y de la época colonial: lo que es nuevo es la toma de conciencia por amplios sectores sociales, incluidos los cultos e intelectuales, de la situación mencionada. Es evidente que los pobres no se inventaron en el Centenario, pues se trata del mismo pueblo mestizo, analfabeto y embrutecido que siempre estuvo ahí y ya había sido descrito por Pérez Rosales, Lastarria, Blest Gana. La novedad es que ahora, a cien años de la Independencia, este grupo de pensadores descubre a ese pueblo como motivo de su protesta.

Es otro vértice importante de la matriz intelectual del Centenario: la percepción de dos países opuestos: uno blanco y otro indígena-mestizo, y de las dificultades de convivir entre sí más allá de los elogios nacionalistas, problemática que se continuará a lo largo del siglo en los textos de Benjamín Subercaseaux, Gabriela Mistral, Luis Oyarzún, quienes procuraron averiguar lo que se oculta bajo el concepto de "pueblo».

Alejandro Venegas reclama al gobierno y a la élite como responsables de la degradación popular, como si esa misma élite que la causó, debiera sacarlos de esa condición con el fin de evitar el desborde social, intentando un conjunto de reformas para evitar la revolución que había conmovido a México o los movimientos revolucionarios en la Rusia zarista. Las revoluciones sociales eran necesarias en algunas circunstancias, pero no en Chile.

Dice Alejandro Venegas: «En nuestro país el pueblo es ignorantísimo y hasta ahora ha sufrido las espoliaciones e inequidades con la tranquilidad pasiva de una bestia de carga; no podemos esperar, pues, su regeneración del ejercicio consciente de sus derechos. No nos queda más caminos que el de México con los inconvenientes de toda autocracia, o el de Rusia con su cortejo de lágrimas, sangre y horrores sin cuento».

Las opiniones de Venegas, como las de Recabarren, impresionaron a su época e hizo que posteriores pensadores las acogieran por la valentía de su denuncia ${ }^{21}$.

Algunos miembros de la élite, como Guillermo Subercaseaux, Francisco A. Encina y Agustín Ross Edwards, pusieron el acento en las reformas económicas, la necesidad de industrialización y la modernización educacional, y allí donde otros ven el tema «moral» y la crisis social, este grupo reflexiona sobre la capacidad (o no) del chileno para asumir 
los desafíos de la modernidad. Son dos ejes que se entrecruzan. Agustín Ross Edwards, por ejemplo, analizó los efectos de la reforma monetaria, planteando la imagen de un Chile rico y muy pobre al mismo tiempo: «Un país bello, sano, productivo, próspero y de brillante condiciones naturales, bajo un aspecto, $y$ bajo otro dominado por una situación monetaria desastrosa, que produce enormes daños» (Ross Edwards, 1911).

Para muchos de ellos, como hemos dicho, la solución a la crisis consistía en realizar una reforma educacional, y la educación fue uno de los temas más analizados para resolver cuestiones como el tipo de educación que se debía aplicar: humanista o técnica, religiosa o laica, europea o norteamericana, memorística o práctica, «cosmopolita», apátrida o nacional, especialista o generalista, etc. A ello se añaden cuestiones adicionales sobre el rol del Estado y el carácter que debía adoptar la universidad en la formación de los futuros ciudadanos.

Como en el caso de la «cuestión social», el debate sobre la educación también venía desde finales del siglo XIX y está presente en los textos de Valentín Letelier, Abelardo Núñez, Eugenio María de Hostos, Eduardo de la Barra, Pedro Balmaceda Toro y algunos otros $^{22}$. Exponer cada una de ellas nos llevaría muy lejos, pero es evidente que la educación conformó un eje central tanto para los pensadores de la época, como para las acciones gubernamentales ${ }^{23}$.

\section{Un nacionalismo (casi) sin pueblo}

Otro tema muy presente es un (paradójico) nacionalismo que actúa como una declaración de amor por la nación, pero con críticas a la propia nación y que se ubica en una de las fuerzas ideológicas más presentes. Para Bernardo Subercaseaux «el nacionalismo es la fuerza cultural dominante del período» (Subercaseaux, 2004, p. 13).

Es decir, para superar la percepción de que nada funciona, con frecuencia se recurrió a una salida de doble rasero: por un lado, se evocó un nacionalismo como una mirada que desde la admiración al país permitiera evitar el escepticismo y encontrar cierta esperanza en el futuro; por otro, ese mismo nacionalismo constituía en una salida retórica que ocultaba un profundo malestar, y que hasta pudo devenir en una creencia sincera.
Salida, en consecuencia, a veces retórica y a veces real, que aplicaron todos con excepción de Recabarren, quien no estuvo dispuesto a utilizar al pueblo en beneficio propio. Otros, en cambio, recurrieron el nacionalismo para explicar al exitoso Chile anterior o para incrementar el miedo a los países vecinos, y el desprecio por la capacidad del inmigrante, que aún en este triste escenario encuentra un lugar apropiado para enriquecerse ${ }^{24}$. $\mathrm{O}$ más aún, para sostener una imagen mítica del indígena y del mestizo.

Pero al caer esa imagen debido a la crisis, solo permaneció la aspiración sin realidad. Por esta razón, no hubo el reconocimiento de un mito fundacional ni héroes individuales o colectivos, como tampoco la aceptación de los primeros habitantes indígenas o solo de forma discursiva. Es decir, no hubo un espacio nacional que sirviera de refugio identitario común.

La perspectiva nacionalista se inicia con el médico Nicolás Palacios, quien en Raza Chilena, establece, como un descubrimiento asombroso, que la raza chilena es mestiza de dos orígenes superiores: de los conquistadores españoles de origen godo y de los araucanos descritos como valientes guerreros, si bien Palacios no prueba lo que dice, pues se basa únicamente en los retratos de los conquistadores, en consideraciones históricas muy generales, o en lingüísticas erróneas.

El producto de esta síntesis, para Palacios, es un país socialmente estructurado y militarmente exitoso. «La raza chilena, como todos saben, es una raza mestiza del conquistador español y del araucano, y vino al mundo en gran número desde los primeros años de la conquista, merced a la extensa poligamia que adoptó en nuestro país el conquistador europeo» (Palacios, 1904, p. 34).

A partir de aquí, comienzan sus (delirantes) interpretaciones raciales, sintetizadas en su opinión de que el chileno es una mezcla de mujer indígena y hombre germano. «El roto chileno es, pues, Araucano-Gótico». Y luego sus largas anotaciones sobre el origen godo de los españoles llegados al Nuevo Mundo.

«El descubridor y conquistador del nuevo mundo vino de España, pero su patria de origen era la costa del mar Báltico, especialmente el sur de Suecia, la Gotia actual. Eran los descendientes directos de aquellos bárbaros rubios, guerreros y conquistadores, que en su éxodo al sur del continente europeo destru-

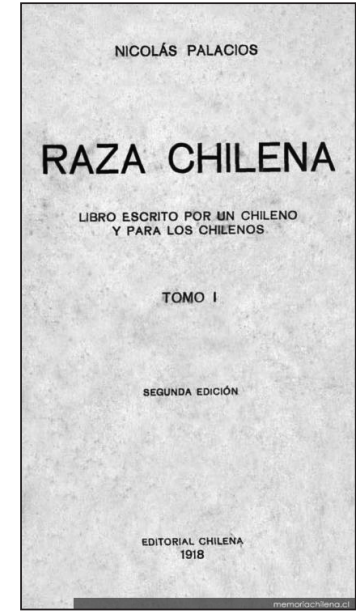

Cubierta de Raza chilena.

22

La bibliografía sobre la educación es muy amplia; ver, entre otros, Eduardo Devés (1999).

23

Vial señala que, en 1902, existían seis escuelas normalistas, donde se formaron aproximadamente 800 profesores, que durante el gobierno del presidente Germán Riesco aumentaron en nueve más. En 1907, el 60\% de la población era analfabeta, la cual hacia 1920 descendió a un $50 \%$. En 1902, la Universidad de Chile sobrepasaba los mil estudiantes, entre los cuales se encontraban los alumnos del Instituto Pedagógico que contaba con más de doscientos cincuento educandos (pp. 138-139).

24

Al hablar de nacionalismo, debemos incluir, entre otras, las reflexiones de Renán sobre la nación como un conjunto de recuerdos y olvidos comunes, y más recientemente a Benedic Anderson (2007), quien asegura que las comunidades nacionales son «imaginadas» porque por su extensión ningún miembro de la misma podría conocer a todos los demás y solo «imaginar» cómo es el resto.

\footnotetext{
Apuntes para un mapa intelectual de Chile durante el Centenario: 1900-1925

F. JAVIER PINEDO
} 


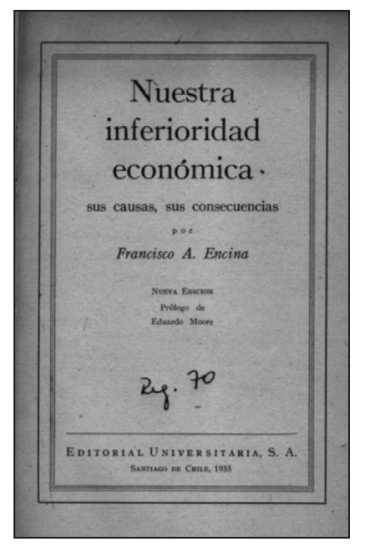

Cubiertas, Nuestra inferioridad económica.

25

Unamuno criticó las posiciones de Palacios señalando que lo extraño no era que el libro se hubiera escrito, sino que tuviera lectores. Dice Unamuno: "Y así es con el libro 'Raza Chilena', obra, en el fondo, de adulación al pueblo chileno y de una endeble científica verdaderamente pasmosa». Titula el artículo como "anónimo», pues Palacios se lo envió ocultando su nombre.

26

Aunque Santiago no era el Buenos Aires que recibía a millones de extranjeros durante los primeros años del siglo, el sentimiento anti inmigración es similar al de aquellos conservadores argentinos que pensaban que la identidad nacional se perdería con la llegada de nuevos individuos, nuevos idiomas y nuevas costumbres (Sarlo, 1988).

Apuntes para un mapa intelectual de Chile durante el Centenario: 1900-1925

F. JAVIER PINEDO yeron el imperio romano de occidente. Eran esos los Godos, prototipo de raza teutónica, germana o nórdica, que conservaron casi del todo pura su casta, gracias al orgullo de su prosapia y a las leyes que, por varios siglos, prohibieron sus matrimonios con las razas conquistadas. Por los numerosos retratos o descripciones que conozco de los conquistadores de Chile, puedo asegurar que a lo sumo el diez por ciento de ellos presentan signos de mestizaje con la raza autóctona de España, con la raza ibera; el resto es de pura sangre teutona, como Pedro de Valdivia, cuyo retrato es $\tan$ conocido».

En Nicolás Palacios, es notorio este doble sentimiento de admiración retórica (él participó en la guerra del Pacífico contra Perú y Bolivia, por lo que celebra la «raza» que ganó el conflicto bélico), y se lamenta al mismo tiempo, por la ausencia de «nacionalidad» que siguió a ese triunfo. Así, y aunque defiende al pueblo del desprecio con que era mirado por autores como Encina, no parece sentirse perteneciente a ese mundo popular que describe desde una mirada exterior: "Yo quiero al roto; sé que es mucho mejor de lo que se le supone; admiro en él el ingenio en la rusticidad y creo que el país será grande si sabe conservar en el roto las preciosas cualidades que le distinguen. Todo consiste en alejarlo en el vicio del licor...». Un racismo nacionalista que mantuvo lectores a lo largo del siglo XX, quienes no vieron lo infundado de sus ideas, como sí lo vio Miguel de Unamuno (1907, pp. 5-6) ${ }^{25}$.

Más tarde, en Decadencia del espíritu de nacionalidad, Palacios señala su rechazo a la llegada de inmigrantes a Chile por las ventajas con que eran tratados respecto a los nacionales: «El hermoso código político de Chile acuerda a los extranjeros mayores garantías que cualesquiera de las constituciones modernas...» (Palacios, 1908) ${ }^{26}$.

Palacios manifiesta elementos conservadores tales como la idealización del ministro Diego Portales en calidad de fundador del Estado chileno a través del orden social constitucional. Se trata de un nacionalismo que abarcó a sectores de la élite, que por conveniencia o por voluntad política hicieron suyo esos planteamientos, como en el caso del libro que escribió Guillermo Subercaseaux (1918), ocho años después del Centenario, y en el que concibe el nacionalismo como un programa válido para resolver los males del país. Guillermo Subercaseaux, proviniendo de un sector social y cultural alto, mantiene el mismo orgulloso sentimiento de nacionalidad y de decepción al mismo tiempo, que hemos expuesto.

Estos textos deben ser considerados como reflexiones de la élite chilena de comienzos de siglo sobre qué proyecto político deben adoptar y qué país quieren construir. En esta búsqueda se puede ser al mismo tiempo liberal (en economía) y conservador (en política y cultura), como lo había sido la clase dirigente durante buena parte del siglo XIX.

Y, por otro lado, los textos nos permiten observar el carácter del nacionalismo chileno como una ideología que oculta las contradicciones sociales: no es la actitud de los mexicanos ante los norteamericanos o de los hindúes frente a los ingleses. Aquí se trata de un discurso para ocultar las diferencias de clases a través de una supuesta igualdad identitaria nacional. Escribe Subercaseaux: «El programa nacionalista ha nacido de un estudio hecho sobre las principales cuestiones del orden económico, social, administrativo e internacional que más interesan a nuestra República en los momentos del presente. [...] El progreso económico de la nación y el mejor aprovechamiento de las riquezas nacionales por los chilenos, he aquí los rumbos más característicos de nuestra política» (Subercaseaux, 1918).

Es decir, este nacionalismo no se constituye en un movimiento de liberación nacional, pues no construye una unión real entre individuos que permanecen separados por cuestiones sociales y culturales. Por ejemplo, el nacionalista Subercaseaux no tiene problemas en reconocer a los Estados Unidos como una nación superior, un error habitual en las élites latinoamericanas, y sugiere que para alcanzar determinados logros educacionales se debe seguir los modelos anglosajones, que funcionan mejor que los propios.

El Centenario produjo también a Francisco A. Encina, quien, además de denunciar la situación social, postuló un proyecto de país que apuntaba en dos direcciones: una económica y otra educacional. Proyecto opuesto al de Luis E. Recabarren, que, a mi juicio, son los dos que mantendrán su vigencia a lo largo del siglo XX.

Encina postula que Chile logró organizar su Estado y alcanzar el desarrollo económico durante la postindependencia, gracias a la acción del autoritario Diego Portales y los 
gobiernos conservadores. Esta situación convirtió a Chile en un país distinto y superior en América latina ${ }^{27}$. En cambio, en 1910, el país vivía una profunda crisis por la falta de ímpetu económico, la inestabilidad política y un sentimiento de nacionalidad mermado.

Como trasfondo, Encina denuncia un sistema educacional basado en una falsa enseñanza «humanista», que evitaba el desarrollo del espíritu empresarial de los jóvenes, derivados hacia las llamadas profesiones liberales (derecho, medicina) las cuales contribuyen menos que las carreras técnicas, el comercio y la industria, al desarrollo económico de Chile. Por otro lado, Encina es uno de los que presenta la peor imagen del pueblo, siguiendo sus negativas teorías racistas tanto de la vertiente hispana (militares que aborrecen del trabajo manual), como indígena (incapaces de imaginar soluciones prácticas), que afectan al estancamiento económico: «El araucano, que no había salido de la barbarie, no sólo tenía invencible repugnancia por el trabajo, sino que aún no había desenvuelto las aptitudes que lo hacen posible».

Así, sobre la base de estos elementos constitutivos, concluye que: «El mestizo que forma el fondo étnico de la población rural, desciende, pues, de progenitores cuya psicología económica era, todavía, rudimentaria» (Encina, 1912). Una negativa psicología económica marcada por «la falta de perseverancia, la obsesión por la fortuna rápida, la incapacidad para el trabajo metódico, la debilidad del espíritu de asociación y cooperación, el derroche del tiempo, etc.»

La solución que propone Encina para superar la crisis radica en organizar un sistema educacional que fomente el espíritu emprendedor, comenzando desde las bases mismas de la educación nacional. Sin embargo, la variedad ideológica de Encina lo hace difícil clasificarlo, pues siendo un estatista no es necesariamente un conservador, pero sí tradicionalista, pro norteamericano, racista, nacionalista y positivista, al mismo tiempo (Pinedo, 2005).

Más aún, Encina agrega la ausencia de un territorio geográfico en Chile que permita levantar una agricultura a gran escala, labor a la que el chileno recurre por comodidad, mientras que debiera dedicarse a la industria. En este contexto, ser nacionalista, insisto, consiste en la construcción de un proyecto político y educacional. Pero un nacionalismo que desconfía del pueblo y de la naturaleza, un nacionalismo como idea abstracta de nación.

En ocasiones algunos de nuestros pensadores actúan con indignación, tomando ellos mismos el protagonismo de la denuncia. Es el caso de Tancredo Pinochet Le-Brun (conocido en la época como Tancrudo Pinochet), quien en cierta ocasión se vistió de obrero agrícola y viajó desde su natal Talca hasta la hacienda del presidente de la República, José Luis Sanfuentes, donde se presentó para pedir trabajo. El relato de esa experiencia la transcribió en el texto Inquilinos en la hacienda de Su Excelencia (1916)28, en el que expone el mal trato dado a los pobres y la necesidad de una nueva educación para alcanzar la nueva sociedad.

«El inquilino chileno, Excelencia, está totalmente divorciado de la vida nacional. Pero ¿quién lo creyera?, tiene hambre de incorporarse a esta vida nacional. Siente hambre de progreso. Tiene un deseo vehemente, vagamente expresado, de salir de su condición de bestia».

El mismo sentido de crítica social manifiesta Tancredo Pinochet en su libro La conquista de Chile en el siglo $X X(1909)^{29}$, que, retomando los planteamientos nacionalistas, rechaza que sean los emigrados extranjeros quienes se benefician de los recursos del país, así como de las ganancias de la industria, comercio y agricultura.

Se trata de una desconfianza que se había iniciado desde la llegada de extranjeros para la colonización del sur de Chile a mediados del siglo XIX y que reflotó, más adelante, con la llegada de profesores alemanes al Instituto Pedagógico, lo cual se expresó en textos como El embrujamiento alemán, de Eduardo de la Barra (1899), el que se burla de la influencia de los maestros alemanes en Chile.

Escribe Pinochet: «El cuerpo docente de los liceos de la República ha sido formado en su mayor parte en el Instituto Pedagógico y este alto centro de educación es dirigido exclusivamente por extranjeros que no se distinguen por su amor a Chile. Cuando fui alumno de este Establecimiento era mi habitual modo de pensar y mi deseo, como así mismo el modo de pensar y el deseo de otros estudiantes que hoy son profesores y rectores de liceos, que Chile fuera más bien una colonia alemana y no una República independiente». Es decir, la ideología de Pinochet está marcada por un
27

Las ideas de Encina fueron acogidas entre pensadores posteriores. Un caso es Alberto Edwards, conocido por su La fronda aristocrática, (1928), que en el artículo «Motines militares» (1919) recoge la tesis planteada por Encina en 1912 para señalar la distancia entre Chile y América latina, pues Chile, en su opinión, se ha mantenido al margen de la anarquía que ha marcado al resto del continente.

28

El texto autobiográfico es una prueba de su condición más de pensador social que de intelectual académico.

29

El libro está dedicado a su madre, "Dedico este trabajo a mi madre, mujer chilena que, para sostener a sus catorce hijos, echó las bases de un Instituto de Educación donde se abrieron nuevos horizontes a las hijas del país y donde cerca de diez mil chilenas han ido a buscar amplitud para su cerebro y grandeza para su corazón».

Apuntes para un mapa intelectual de Chile durante el Centenario: 1900-1925

F. JAVIER PINEDO 
nacionalismo no conservador ni racista, pero sí como un pensamiento y una acción para alcanzar la justicia social.

Como hemos dicho, se trata de ensayistas que recurren a ideologías diversas, actitud propia de pensadores vivenciales y no necesariamente académicos. Incluso en otro momento asumirá la posición de los hispanistas que más tarde serán capitaneados por Jaime Eyzaguirre, al establecer las diferencias entre el proyecto de modernidad hispano y sajón.

«Nosotros somos una nación caballeresca que vibra siempre al unísono de los más refinados sentimientos de humanidad y altruismo, razón por la cual, cuando vemos que un país toma medidas, dictadas por su egoísmo nacional, tendientes a favorecer a sus ciudadanos contra los intereses de los extranjeros, prorrumpen nuestros distinguidos diaristas en exclamaciones de sorpresa, condenando las nuevas medidas como retrógradas o medievales».

Respecto a su nacionalismo incluimos una cita de lo que habitualmente ha sido visto como representativo de esa posición. «Al hijo del pueblo chileno lo tratamos con desprecio, lo dejamos morirse en los conventillos, o lo desterramos para dar cabida en nuestro suelo al inmigrante europeo a quien reservamos todos nuestros favores». Exactamente lo opuesto a Encina y sin coincidir completamente con Palacios.

Se trata de un pensamiento contradictorio $\mathrm{y}$ vital que va creando un proyecto personal y voluntarioso para levantar la identidad chilena, tomando de aquí y de allá ciertos rasgos históricos o del carácter social nacional, y, sin dejar de mencionar los defectos de sus compatriotas, pues el grupo destinatario de su crítica lo compone una gama muy amplia de chilenos e instituciones que incluye a políticos, el Estado, la mala educación, la oligarquía, y, sobre todo, la sensación de que en Chile nada funciona. Un intenso sentimiento de vivir como extranjero en un país (el propio) no preparado para el combate de la modernidad. En el contexto global del Centenario, Tancredo Pinochet coincide en que el tema de la decadencia nacional podía una vez más corresponder a una visión en ocasiones, exagerada, pues el país terminaba de salir triunfador de una guerra en la que había ganado enormes territorios a los países vecinos: «Todo se nos va. Para el norte, entregamos el salitre de las pampas que hemos regado con nuestra san- gre; al sur regalamos los tupidos follajes de nuestras selvas vírgenes; al oriente cedemos las entrañas de nuestra nevada cordillera, y al poniente abandonamos las olas bulliciosas que bañan nuestras playas y que sólo surcan barcos extranjeros».

Esta imagen de debilidad y decadencia (real o no) es contrastada por nuestros pensadores con el pasado chileno considerado como glorioso. Escribe Pinochet: «Hace siglos conquistó esta tierra de Chile el primer país de Europa en aquel entonces: lo conquistó con arcabuces, lanzas y culebrinas. Hoy lo conquista los países que han sucedido a España en el poderío, pero no ya con arcabuces, lanzas y culebrinas, las armas de entonces, sino con trabajo y capital, las armas de ahora» (Pinochet, 1909). Y concluye amargamente que «[...] esta derrota de Chile en las batallas modernas del trabajo y la inteligencia no se debe a la flojedad, cobardía o raquitismo de las tropas, sino a la falta de patriotismo...» (Pinochet, 1909).

Es un tópico de la época: por una parte, percibir que este país, a cien años de la Independencia, provocaba un balance lastimero y negativo. Pero, frente a esa antiidentidad, es la idea imaginada de nación, voluntariosa y muchas veces cultural, la que se propone como proyecto colectivo para superar los problemas reales: es lo que denominamos como un «nacionalismo sin pueblo».

\section{Conclusiones}

Como hemos visto, las ideas de los pensadores del Centenario están estructuradas en torno a la crisis social, la reforma educacional, el nacionalismo y la identidad nacional. Temas en los que, sin estar plenamente de acuerdo, coinciden cuando establecen un diagnóstico negativo de la realidad nacional; pero no en las soluciones propuestas que incluyen el desarrollismo, el cristianismo social (la encíclica Rerum Novarum, de León XIII), el pensamiento laico, el nacionalismo y el socialismo europeo.

A partir del Centenario, Chile avanzó hacia una cultura y una política doble: por un lado, cada vez más mesocrática y popular, más estatista, antielitaria y anticapitalista. Y, por otro, desarrollista, antipopular, individualista, pronorteamericana.

Un Chile oficial y otro alternativo: el oficial trata de mantener una continuidad en el 
modelo con algunas reformas puntuales. El alternativo, sostenido por las bases populares y sectores de la clase media, intenta modificar radicalmente la economía, la educación, la propiedad y el sistema político. Sin embargo, ninguno de los dos funcionó por sí mismo ni respecto a lo que ofrecía al sector contrario, aunque mantuvieron frecuentes choques políticos e intelectuales. Un esquema, éste, que se cierra el año 1973 con el golpe militar del general Pinochet quien intentó poner fin a esos debates políticos.

Pero el Chile de 1910 es, a su vez, un país en búsqueda de una identidad nacional que modele una nación reconocible para todos y que permita, detrás de esa identidad, caminar hacia el futuro. Es tan intensa la intervención de estos pensadores en esa realidad social, que Bernardo Subercaseaux (1988) habla de una «invención intelectual de la Nación». Esta búsqueda identitaria se planteará como un conflicto de «metáforas» e intereses reales, asumiendo, más allá del aislamiento del país, una antigua tradición latinoamericana: la culturización de la política.

\section{Bibliografía}

Anderson, Benedict (2007), Comunidades imaginadas. Reflexiones sobre el origen y la difusión del nacionalismo, México, FCE.

Barros, Luis y Vergara, Ximena (1978), El modo de ser aristocrático. El caso de la oligarquía chilena hacia 1900, Ediciones Aconcagua, Santiago.

Cruzar, Ximena y Tironi, Ana (1999), «El pensamiento frente a la cuestión social en Chile», en E. Devés, J. Pinedo, R. Sagredo, El pensamiento chileno en el siglo XX, México, FCE.

Da Costa, Miguel (1999), «El pensamiento de Enrique Molina Garmendia», en E. Devés, J. Pinedo, R. Sagredo, El pensamiento chileno en el siglo $X X$, México, FCE.

Daistman, Andy (1999), «Prosiguiendo sucesivamente, sin interrupción, el orden numérico. Escritor y sociedad en Talca hacia el siglo XX», Universum, Universidad de Talca, $\mathrm{N}^{\circ} 14$.

De Costa, René (2011), «Una carta inédita de José Enrique Rodó», Revista Iberoamericana, Vol. LXXVII, $\mathrm{N}^{\circ} 235$, abril-junio 2011.
De la Barra, Eduardo (1899), El embrujamiento alemán, Santiago de Chile, Establecimiento Poligráfico Roma.

De Ramón, Armando (1985), «Estudio de una periferia urbana: Santiago de Chile. 18501900», en Historia, Universidad Católica de Chile, $\mathrm{N}^{\circ} 20$, Santiago.

Devés, Eduardo (1999), «Pensadores chilenos en el debate de fin de siglo», Universum, Universidad de Talca, $\mathrm{N}^{\circ} 14$.

Donoso, Ricardo (1963), «El Instituto Pedagógico. Tres generaciones de maestros. Discurso pronunciado con motivo de la incorporación como miembro académico de la Facultad de Filosofía y Educación de la Universidad de Chile», Separata de Atenea, $\mathrm{N}^{\circ} 401$, Concepción.

Edwards, Alberto (1924), Fronda Aristocrática.

Encina, Francisco A. (1912), Nuestra inferioridad económica, Santiago, Universitaria.

- (1960), «El pueblo chileno hacia 1810», Anales de la Universidad de Chile, $\mathrm{N}^{\circ}$ 119.Citado por, Eduardo Devés (1999), «Pensadores chilenos en el debate de fin de siglo», Universum, Universidad de Talca, $\mathrm{N}^{\circ} 14$, p. 78.

Gazmuri, Cristián, «Bicentenario. Centenario y reflexión", en Instituto de Historia de la Universidad Católica de Chile, http:// www.hist.puc.cl/cinfo/Articulos/gazmuri25.html

Godoy, Hernán (1973), «El pensamiento nacionalista en Chile a comienzos del siglo XX», Santiago de Chile, Revista Dilemas, $\mathrm{N}^{\circ}$ 9. El texto se reeditó en E. Devés, J. Pinedo, R. Sagredo (1999), El pensamiento chileno del siglo $X X$, México, FCE. Cito por esta última edición.

Grez Toso, Sergio (1995), La «cuestión social» en Chile. Ideas y debates precursores (1804-1902), DIBAM. Santiago, Chile.

Kaempfer, Álvaro (2011), «1910. Balance y perspectivas: Luis Emilio Recabarren y Alejandro Venegas ante el Centenario", Arancaria, Revista Iberoamericana de Filosofía, Política y Humanidades, año 13, $\mathrm{n}^{\circ} 25$, primer semestre.

Marsal, Juan F. (ed.) (1970), El intelectual latinoamericano, Instituto Torcuato di Tella, Bs. Aires.

Mac Iver, Enrique (1900), «Discurso sobre la crisis moral de la República», pronunciado en el Ateneo de Santiago el 1 de agosto de 1900. Publicado como Crisis moral de la República, Santiago, Imprenta Moderna.

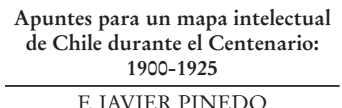

F. JAVIER PINEDO 
Palacios, Nicolás (1904), Raza Chilena. Libro escrito por un chileno y para los chilenos, Santiago, Ed., Chilena.

- (1908), Decadencia del espíritu de nacionalidad, 1908.

Pinedo, Javier (2005), «El pensamiento de los ensayistas y cientistas sociales en los largos años 60 en Chile (1958-1973). Los herederos de Francisco A. Encina», Revista Atenea, Universidad de Concepción, $\mathrm{N}^{\circ}$ 492, II semestre.

Pinochet, Le-Brun, Tancredo (1916), Inquilinos en la hacienda de Su Excelencia, Santiago, Casa Editora.

- (1909), La Conquista de Chile en el siglo $X X$, Santiago, Imprenta, La Ilustración.

Recabarren, Luis Emilio (1910), El balance del siglo. Ricos y pobres a través de un siglo de vida republicana, Santiago.

Rodó, José Enrique (1975), El Centenario en Chile. Discurso pronunciado, en representación del Uruguay, en la sesión solemne celebrada por el congreso chileno, durante las fiestas del Centenario, el 17 de septiembre de 1910, Montevideo, Impresora Uruguaya, Colombino S.A.

Rodríguez Mendoza, Emilio (1899), Ante la decadencia, Editorial Moderna, Santiago.

Ross Edwards, Agustín (1911), Sesenta años de cuestiones monetarias y financieras $y$ problemas bancarios, Santiago de Chile, Encuadernación Barcelona.

Sánchez, Cecilia (1999), «La sociedad chilena en la escena del médico de provincia», Universum, Universidad de Talca, $\mathrm{N}^{\circ} 14$.

Sarlo, Beatriz (1988), Una modernidad periférica: Buenos Aires 1920 y 1930, Buenos Aires, Nueva visión.

Stabili, María Rosalia (2003), El sentimiento aristocrático. Élites chilenas frente al espejo (1860-1960), Santiago, Andrés Bello.

Subercaseaux, Guillermo (1918), Los ideales nacionalistas. Ante el doctrinarismo de nuestros partidos politicos históricos, Santiago, Editorial Universitaria.

Subercaseaux, Bernardo (1988), Fin de Siglo. La época de Balmaceda, Santiago, Aconcagua.

- (2004), Historia de las ideas y de la cultura en Chile. El centenario y las vanguardias. Tomo III, Santiago, Universitaria.

Unamuno, Miguel (1907), «Sobre el libro anónimo 'Raza Chilena'», en El diario Ilustrado, Santiago, 4 de agosto de 1907.

Valdés Cange, Dr. J. (1910), Sinceridad. Chile intimo en 1910, Santiago, Editorial Universitaria.

Fecha de recepción: 10/07/2011

Fecha de aprobación: 24/10/2011
Apuntes para un mapa intelectual de Chile durante el Centenario: 1900-1925

F. JAVIER PINEDO 